\title{
NANOESTRUTURAS DE $\beta$-LACTOGLOBULINA E SUA CAPACIDADE DE ENCAPSULAR MOLÉCULAS BIOATIVAS
}

\author{
R. N. DA COSTA ${ }^{1}$, W. C. LAURINDO ${ }^{1}$, J. S. R. COIMBRA ${ }^{2}$, A. B. MAGESTE ${ }^{3}$ e I. J. B. \\ SANTOS $^{1}$
}
${ }^{1}$ Universidade Federal de São João Del-Rei, Departamento de Química, Biotecnologia e Engenharia de Bioprocessos
${ }^{2}$ Universidade Federal de Viçosa, Departamento de Tecnologia em Alimentos
${ }^{3}$ Universidade Federal de Ouro Preto, Departamento de Química
E-mail para contato: igorboggione@ufsj.edu.br

\begin{abstract}
RESUMO - As proteínas do soro do leite além de apresentar alto valor nutricional, também apresenta propriedades técnico-funcionais interessantes para a indústria de alimentos. Portanto, o presente trabalho visa otimizar a obtenção de nanoestrutura de $\beta$-lactoglobulina, proteína do soro do leite, e aplicá-la como dispositivo encapsulador das moléculas bioativas, Quercetina e Vitamina B2. Obteve-se a melhor nanoestrutura com tamanho de $109,95 \mathrm{~nm}$, por conseguinte, avaliou-se a propriedades ténico-funcionais de espuma e emulsão. $\mathrm{O}$ primeiro mostrou que a espuma formada pela proteína nanoestruturada possui estabilidade maior que a espuma formada pela proteína pura. $\mathrm{O}$ mesmo foi observado no teste de emulsão. A encapsulação do bioativo Quercetina apresentou eficiência de 85,16\%. Entretanto, para a vitamina B2 não se obteve eficiência na encapsulação, sugerindo a hidrofobicidade da nanoestrutura de $\beta$-lactoglobulina. De modo geral, a $\beta$ lactoglobulina mostrou-se um excelente dispositivo encapsulador da quercetina.
\end{abstract}

\section{INTRODUÇÃO}

Atualmente, o Brasil é um dos grandes produtores de leite no mundo, ocupando em 2014 a $5^{\text {a }}$ colocação segundo o USDA (United States Department of Agriculture). Isto deve, ao aumento populacional que acarreta o maior consumo, levando à maior produtividade. Porém, para satisfazer essa demanda, as indústrias investem em tecnologias para elevar o volume de leite produzido, sendo que no Brasil, em 14 anos, o volume de leite quase dobrou, segundo o IBGE (PRESTES; PAYES, 2012; MILKPOINT, 2016).

Paralelamente ao crescimento leiteiro, há crescimento de seus derivados, como o queijo. Contudo, esse crescimento é preocupante, uma vez que para cada $1 \mathrm{~kg}$ de queijo gera-se $9 \mathrm{~kg}$ de soro. Este é prejudicial à natureza, pois há um potencial poluidor grande, se despejado sem tratamento (MILKPOINT, 2016; OLIVEIRA; BRAVO; TONIAL, 2012). Apesar dessas consequências muitas indústrias ainda descartam inadequadamente esse soro (OLIVEIRA et al.,2012).

Devido a isso, a nanotecnologia surge como uma alternativa promissora para contornar o impacto gerado (OLIVEIRA et al., 2012; ZAVAREZE et al., 2010; ANTUNES, 2003), uma vez que as nanoestruturas de proteínas do soro do leite são consideradas seguras e possuem o potencial transportador e protetor de substâncias funcionais, são de alto valor nutricional e 
apresentam propriedades técnico-funcionais interessantes para a indústria de alimentos (ABD EL-SALAM; EL-SHIBINY, 2012).

Dessa forma, os nutracêuticos, moléculas bioativas com propriedades nutricionais e farmacológicas, podem ser encapsuladas nessas nanoestruturas, aumentando sua biodisponibilidade no organismo. Assim, este trabalho propõe avaliar a obtenção e caracterização de nanoestruturas de $\beta$-lg, determinação de suas propriedades técnico-funcionais sua eficiência de encapsular a Querceina e a Vitamina B2, dois nutrientes importantes para o ser humano.

\section{MATERIAL E MÉTODOS}

\subsection{Material}

A $\beta-1 \mathrm{~g}$ foi gentilmente cedida pela Davisco Foods International (Minnesota, EUA).A Quercetina e a Vitamina B2 foram adquiridas da Sigma Aldrich (Missouri, EUA).O NaCl era de grau analítico da Exodus Scientific (São Paulo, Brasil). A água destilada foi purificada por osmose inversa Hidrotek (Santa Iria de Azóia, Portugal). E os outros reagentes foram de grau analítico sem purificações adicionais.

\subsection{Métodos}

Delineamento Experimental: as nanoestruturas de de $\beta$-lactoglobulina foram obtidas via tratamento Box-Behnken com as variáveis temperatura, $\mathrm{NaCl}$ e tempo de aquecimento (Tabela $1)$.

Tabela 1 - Condições usadas no delineamento experimental para formação de $\beta$-lg nanoestrutura.

\begin{tabular}{|c|c|c|c|}
\hline NPs* & Temperatura $\left({ }^{\circ} \mathbf{C}\right)$ & Tempo (min) & NaCl $\left(\mathbf{m m o l}_{\mathbf{~}} \mathbf{~}^{\mathbf{1}}\right)$ \\
\hline 1 & 62,5 & 120 & 0 \\
\hline 2 & 25 & 60 & 0 \\
\hline 3 & 100 & 60 & 0 \\
\hline 4 & 62,5 & 120 & 50 \\
\hline 5 & 62,5 & 60 & 25 \\
\hline 6 & 100 & 120 & 50 \\
\hline 7 & 25 & 60 & 25 \\
\hline 8 & 100 & 10 & 25 \\
\hline 9 & 25 & 120 & 50 \\
\hline 10 & 62,5 & 10 & 25 \\
\hline 11 & 62,5 & 60 & 25 \\
\hline 12 & 25 & 10 & 0 \\
\hline 13 & 62,5 & 10 & 25 \\
\hline 14 & 62,5 & 60 & 50 \\
\hline 15 & 100 & 60 & \\
\hline
\end{tabular}

Teste de Espuma: amostras de nanoestrutura foram homogeneizadas em Ultra Turrax (Biovera, Brasil), com posterior medição da altura da espuma em intervalos de tempo para calcular o aumento de volume (VI) e estabilidade da espuma (FS), pelas as equações 1 e 2. 


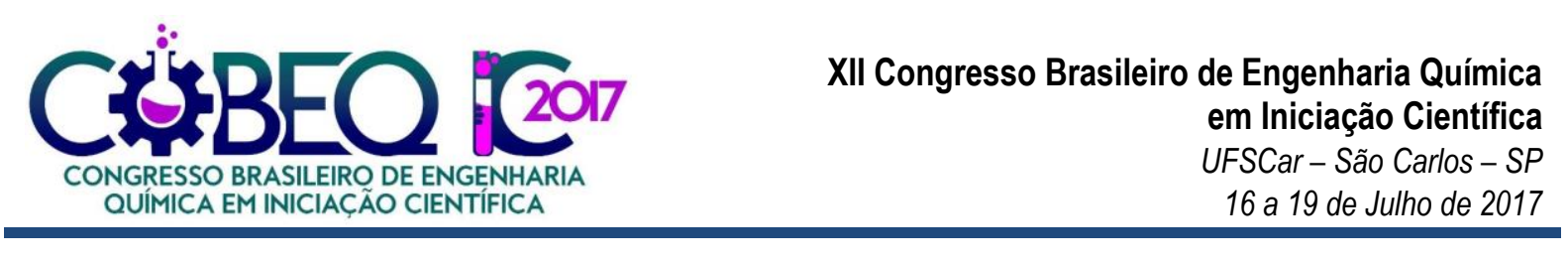

$$
\begin{aligned}
& V I=\left[\frac{\left(\frac{V_{T}}{V_{E}}\right)-V_{T}}{V_{T}}\right] x 100 \\
& F S=\left(\frac{V_{E_{t}}}{V_{E_{t 0}}}\right)
\end{aligned}
$$

No qual $V_{t}$ é o volume total da solução, e é volume da espuma e $V_{E t}$ e $V_{E t 0}$ são volumes de espuma correspondente ao tempo t (30,60 e $120 \mathrm{~min})$ e tempo zero, respectivamente.

Teste de Emulsão: O Índice de Atividade do Emulsionante (IAE) da proteína nativa e nanoestruturada foi determinado segundo CAMERON et al. (1991). Para isso, óleo de girassol, água destilada e dispersão de proteína foram agitados em Ultra Turrax. Em intervalos de tempo, retirou-se alíquotas do fundo de cada emulsão, diluiu-se em solução de SDS a $0,1 \%(\mathrm{~m} / \mathrm{v})$ e a absorvância foi medida a $500 \mathrm{~nm}$ em um espectrofotômetro UV-Vis Global Trade Technology (São Paulo, Brasil). O IAE e a estabilidade da espuma (ESI) foram calculados de acordo com a Equação 3 e 4, respectivamente.

$$
\begin{aligned}
& I A E\left(m^{2} g^{-1}\right)=\frac{2 \times 2,303 \times A_{0} \times F D}{c \times(1-\theta) \times 1000} \\
& E S I=\frac{A_{0}}{A_{0}-A_{t}}
\end{aligned}
$$

No qual $A_{0}$ é absorbância da emulsão diluída no tempo zero, FD é fator de diluição, c é a concentração inicial da proteína $(\mathrm{g} / \mathrm{mL})$ e $\theta$ é fração do óleo para formar emulsão.

Encapsulação: adicionou-se diferentes concentrações de quercetina e vitamina B2 em microtubos previamente pesados, juntamente com a dispersão de nanoestrutura de proteína. Ressalta-se que Quercetina e Vitamina B2 foram encapsuladas separadamente. Agitou-se as amostras manualmente por 5 minutos, centrifugou-se e recolheu-se e diluiu-se o sobrenadante para leitura no espectrofotômetro UV-Vis a $373 \mathrm{~nm}$ (Quercetina) e $445 \mathrm{~nm}$ (Vitamina B2) para obtenção da eficiência da encapsulação EE (\%) pela equação 5. Incubou-se o pellet em estufa a $50{ }^{\circ} \mathrm{C}$ por 48 horas para secagem e posterior pesagem. Pela subtração da massa de cada eppendorffs obtém o valor de $\mathrm{W}_{\mathrm{np}}$ na equação 6 . Então, o valor da capacidade de ligação (LC) somente da quercetina na nanoestrutura foi calculado pela equação 6 .

$$
\begin{aligned}
& E E(\%)=\left(W_{\text {total }}-W_{\text {livre }}\right) 100 / W_{\text {total }} \\
& C(L C(\%))=\left(W_{\text {total }}-W_{\text {livre }}\right) 100 / W_{n p}
\end{aligned}
$$

\section{RESULTADOS}

\subsection{Delineamento Experimental}

A Tabela 2 mostra os tamanhos e o índice de polidispersividade das estruturas obtidas pelo tratamento térmico.

Tabela 2 - Valores de Tamanho (nm) e PDI (Polidispersividade) das amostras analisadas no equipamento Nanozeta Sizer Malvern (Inglaterra, Reino Unido). 


\begin{tabular}{|c|c|c|}
\hline $\begin{array}{l}\text { CONGRESSC } \\
\text { QUIIMICA }\end{array}$ & \multicolumn{2}{|c|}{ 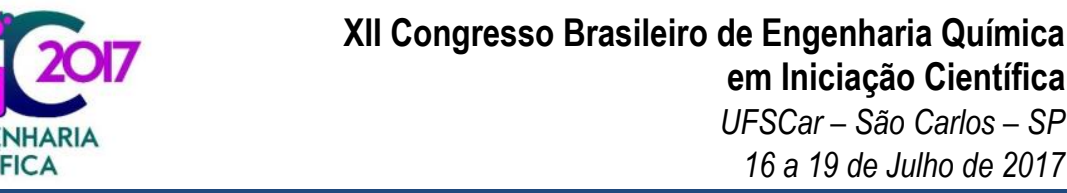 } \\
\hline NP's & $\begin{array}{c}\text { Tamanho }(\mathrm{nm}) \\
\text { Média } \pm \mathrm{Sd}\end{array}$ & $\begin{array}{c}\text { PDI } \\
\text { Média } \pm \mathrm{Sd}\end{array}$ \\
\hline 1 & $356,62 \pm 58,07$ & $0,4315 \pm 0,0319$ \\
\hline 2 & $285,13 \pm 63,35$ & $0,5745 \pm 0,1889$ \\
\hline 3 & $581,70 \pm 180,12$ & $0,6203 \pm 0,1261$ \\
\hline 4 & $416,37 \pm 71,42$ & $0,4750 \pm 0,0733$ \\
\hline 5 & $204,40 \pm 80,80$ & $0,3422 \pm 0,0451$ \\
\hline 6 & $105,00 \pm 13,71$ & $0,4328 \pm 0,0484$ \\
\hline 7 & $142,52 \pm 22,31$ & $0,4308 \pm 0,0542$ \\
\hline 8 & $159,73 \pm 41,37$ & $0,3982 \pm 0,0449$ \\
\hline 9 & $178,78 \pm 69,43$ & $0,3412 \pm 0,0488$ \\
\hline 10 & $274,16 \pm 174,14$ & $0,4353 \pm 0,1853$ \\
\hline 11 & $147,24 \pm 59,38$ & $0,3093 \pm 0,0353$ \\
\hline 12 & $363,83 \pm 224,38$ & $0,4235 \pm 0,1404$ \\
\hline 13 & $349,47 \pm 106,88$ & $0,5662 \pm 0,2079$ \\
\hline 14 & $177,66 \pm 96,06$ & $0,2970 \pm 0,0590$ \\
\hline 15 & $109,95 \pm 0,68$ & $0,4062 \pm 0,0539$ \\
\hline
\end{tabular}

Em acordo com USKOKOVIĆ (2007), nanoestruturas são materiais com tamanho entre $1 \mathrm{a} 300 \mathrm{~nm}$. Portanto, a melhor nanoestrutura obtida foi no tratamento $15 \mathrm{com}$ o tamanho de 109,95 nm e PDI (Polidispersividade) de 0,4062. Segundo Madalena et al. (2016), o PDI próximo de 0,4 indica boa polidispersividade. Portanto, os demais testes foram realizados com a nanoestrutura do tratamento 15 .

\subsection{Teste de espuma}

A Tabela 3 mostra a estabilidade da espuma das nanoestruturas obtidas e da proteína nativa.

Tabela 3 - Valores de VI e FS obtidos para cada amostra. Onde FS30, FS60 e FS120 são os valores de FS nos intervalos 30, 60 e 120 min, respectivamente.

\begin{tabular}{|c|c|c|}
\hline & Proteína Pura & Nanoestrutura \\
\hline VI & $16,98 \pm 0,71$ & $21,43 \pm 1,41$ \\
\hline FS30 & $22,22 \pm 0$ & $66,67 \pm 0$ \\
\hline FS60 & $7,78 \pm 0,21$ & $50,00 \pm 0$ \\
\hline FS120 & $0,00 \pm 0$ & $33,33 \pm 0$ \\
\hline
\end{tabular}

A nanoestrutura obteve uma melhor propriedade de espuma que a proteína nativa. Este resultado é corroborado por LEMAN; DOGA (2003), os quais constataram que o tratamento térmico da $\beta$-lactoglobulina, não nanoestruturada, provoca a diminuição da capacidade de formação de espuma, enquanto que essa característica é aumentada para a proteína nanoestruturada.

\subsection{Teste de emulsão}

A Tabela 4 mostra a propriedade emulsificante da nanoestrutura obtida em relação à proteína nativa.

Tabela 4 - Valores de IAE $\left(\mathrm{m}^{2} \mathrm{~g}^{-1}\right)$ e ESI para a nanoestrutura e proteína pura.

\begin{tabular}{|c|c|c|}
\hline & Nanoestrutura & Proteína Pura \\
\hline IAE (m2g-1) & 118 & 152,91 \\
\hline ESI & 192 & 124,5 \\
\hline
\end{tabular}


Apesar do Índice de Atividade Emulsificante (IAE) da nanoestrutura ter sido baixo se comparado ao da proteína pura, seu valor de Estabilidade da Emulsão (ESI) foi maior. O ESI é de maior interesse, pois prova que a nanoestrutura tem maior capacidade de estabilizar a emulsão ao longo do tempo.

\subsection{Encapsulamento}

A Tabela 5 mostra a eficiência de encapsulação e a capacidade de ligação da quercetina nas nanoestruturas obtidas.

Tabela 5- Eficiência de encapsulação EE(\%) em função da concentração de Quercetina na disperção de $\beta$-lg.

\begin{tabular}{|c|c|c|}
\hline $\begin{array}{c}\text { Concentração de Quercetina } \\
\left(\mu \mathrm{g} \cdot \mathrm{ml}^{-1}\right)\end{array}$ & $\mathrm{EE}(\%)$ & LC $(\%)$ \\
\hline 25 & 17,13095 & 6,9081 \\
\hline 50 & 38,7197 & 8,1275 \\
\hline 100 & 59,022 & 17,7053 \\
\hline 150 & 67,1004 & 31,78357 \\
\hline 300 & 85,1651 & 40,7551 \\
\hline 600 & 83,5386 & 41,6298 \\
\hline
\end{tabular}

A nanoestrutura de $\beta$-lg foi capaz de encapsular a quercetina, composto hifrofóbico, com eficiência máxima de $85,16 \%$, porém não encapsulou a vitamina B2, hidrofílica. Portanto, isto sugere que a $\beta$-lg nanoestruturada apresenta uma superfície hidrofóbica.

A maior eficiência de encapsulação $[\mathrm{EE}(\%)]$ está relacionada à maior capacidade de ligação [LC(\%)], pois quanto maior $\mathrm{EE}(\%)$ maior o $\mathrm{LC}(\%)$. Não foi possível comparar os resultados obtidos com dados disponíveis na literatura, uma vez que nenhum trabalho com este sistema foi publicado até o momento. No entanto, Souza et al. (2014) obteve EE(\%) superior a 95\% encapsulando quercetina com nanopartículas de lecitina/quitosana, com concentrações variadas de quercetina $(50,70$ e $100 \mu \mathrm{g} / \mathrm{mL})$. Apesar de no presente trabalho o dispositivo encapsulador ter sido diferente (nanopartículas de $\beta-\lg$ ), ambos resultados foram obtidos com sucesso.

\section{CONCLUSÃO}

Nanoestruturas de $\beta$-lactoglobulina foram obtidas sob as condições de $100^{\circ} \mathrm{C}, \mathrm{NaCl}$ a $50 \mathrm{mmol}$ L-1 por 60 minutos. As nanoestruturas possibilitaram uma eficientemente encapsulação da quercetina, $85,16 \%$, o que sugere que a superfície da nanoestrutura é hidrofóbica. Os experimentos mostraram ainda, que as nanoestruturas de $\beta-\lg$ possuem significativa estabilidade de espuma e emulsão. Além disso, os resultados sugerem que a encapsulação de quercetina por nanopartículas de $\beta$-lg pode ser utilizado como uma alternativa pertinente na adição de nutracêuticos aos alimentos, como também uma maneira de proteger a molécula bioativa contra condições adversas no processamento industrial e tornar mais eficiente a sua liberação e absorção no organismo.

\section{REFERÊNCIAS}


ABD EL-SALAM, M. H.; EL-SHIBINY, S. Formation and potential uses of milk proteins as nano delivery vehicles for nutraceuticals: A review. International Journal of Diary Technology, Dairy Department, National Research Centre, Dokki, Cairo, Egypt, v. 65, n. $1,2012$.

ANTUNES, A. J. Funcionalidade de Proteínas do Soro de Leite Bovino. 1. ed. 1. Barueri: Manole, p. 142, 2003.

CAMERON, D. R.; WEBER, M.E.; IDZIAK, E.S.; NEUFELD, R.J.; COOPER, D.G. Determination of interfacial areas in emulsions using turbidimetric and droplet size data: correction of the formula for emulsifying activity index. Journal of Agricultural and Food Chemistry, Washington, v.39, n.4, p.655-659, Apr. 1991.

LEMAN, J.; DOGA, T. Effect of temperatura and high pressure on the foaming properties of beta-lactoglobulin salted out at pH 2. Commun Agric Appl Biol Sci, v. 68, n. 2, pt. B, p. 489-492, 2003.

MADALENA, D. A.; RAMOS, O. L.; PEREIRA, R. N.; BOURBON, A. I.; PINHEIRO, A. C.; XAVIER MALCATA, F.; TEIXEIRA, J. A.; VICENTE, A. A. In vitro digestion and stability assessment of $\beta$-lactoglobulin/riboflavin nanostructures. Food Hydrocolloids, Portugal, v. 58, p. 89-97, 2016.

MILKPOINT. As grandes oportunidades do mercado de queijos no Brasil. Disponível em <http://www.milkpoint.com.br/industria/radar-tecnico/mercado/as-grandesoportunidades-do-mercado-de-queijos-no-brasil-93301n.aspx> Acesso em: 18 de julho de 2016.

OLIVEIRA, D. F.; BRAVO, C. E. C.; TONIAL, I. B. Soro de leite: um subproduto valioso. Revista do Instituto de Laticínios Cândido Tostes, Paraná, v. 67, n. 385, p. 64-71, mar. /abr., 2012.

PRESTES, M. J.; PAYES, M. A. M. Crescimento da indústria de laticínios no Brasil. Sorocaba, SP, 2012. 19p.

SOUZA, M. P.; VAZ, A. F. M.; CORREIA, M. T. S.; CERQUEIRA, M. A.; VICENTE, A. A.; CARNEIRO-DA-CUNHA, M. G. Quercetin-Loaded Lecithin/Chitosan nanoparticles for functional food appplications. Food Bioprocess Technol, Nova York, v. 7, p. 1149-1179, 2014.

TAVARES, G. M.; CROGUENNEC, T.; CARVALHO, A. F.; BOUHALLAB, S. Milk protein as encapsulation devices and delivery vehicles: Applications and trends. Trends in Food Science \& Technology, Rennes, France, v. 37, p. 5-20, 2014.

USKOKOVIĆ, V. Nanotechnologies: What we do not know. Technology in Society v. 29, n. 1, p. 43-61, 2007.

ZAVAREZE, E. R.; MORAES, K. S.; SALAS- MELLADO, M. M. Qualidade tecnológica e sensorial de bolos elaborados com soro de leite. Ciência e Tecnologia de Alimentos, v.30, n.1, p.102-106, 2010. 